\title{
6 Age division and ageism in the public debates regarding COVID-19
}

\author{
Intergenerational solidarity and \\ antagonisms in the era of the \\ coronavirus pandemic ${ }^{1}$
}

\author{
Jaroslava Hasmanová Marhánková
}

The fact that coronavirus disease 2019 (COVID-19) affects age groups differently, has impacted the wider introduction of age-based measures and restrictions as part of the strategy to minimise the negative outcomes of the pandemic. It also led to a re-labelling of intergenerational encounters as a major risk factor for older people. The idea that age-based lockdowns (or other strategies involving age segregation) could be a possible solution gained a rather prominent position in the discussions regarding economically sustainable solutions to the pandemic. These debates bring fundamental challenges for gerontology and related disciplines, within which there is a long-term consensus on the benefits and fundamentally positive role of intergenerational ties.

\section{Introduction}

In December 2019, the World Health Organisation (WHO) first reported the occurrence of cases of a new form of respiratory disease in Wuhan in China. On the 11th of February, the general director of World Health Organization (WHO) announced that this disease would be named COVID-19 as an acronym for 'coronavirus disease 2019'. The statistically different rates at which serious manifestations of COVID-19 are experienced by different age groups represents one of the most significant features of this pandemic, which also shapes its media image. ${ }^{2}$ One of the most widely read national newspapers in the Czech Republic, for example, referred to the coronavirus in one of its headlines as 'the disease of the old, which mercifully omits children'. 3 As Gilleard and Higgs (2020) pointed out, our current knowledge regarding the effects of this disease suggest that it does amplify but does not change the chronology of life and death. If this disease were to significantly 
change the chronology of life and death, its social and psychological effects would probably be fundamentally different and, in many ways, more dramatic. This fact made it possible to symbolically incorporate COVID-19 into the course of life, not necessarily as a natural part of it, but at least as something that does not contradict the order of things. It is, therefore, not surprising that the emphasis on the fact that the serious progression of the disease mainly affects older people appears as such an essential part of the representation of this pandemic. The reference to chronological age has become an integral component of reports of deaths caused by COVID-19. In the subtext, it is also an essential element of efforts to calm the exaggerated atmosphere of fear. Reference to the fact that the fatal impact of the disease especially affects older people makes constantly visible the evidence that nothing changes significantly in the 'chronology of life and death'. The importance of membership in certain age groups, thus, has become the distinguishing feature of the pandemic. From the beginning, the COVID-19 epidemic has been portrayed primarily as a 'problem of the elderly' (Ayalon, 2020).

The essentialization of chronological age as a synonym for risk and definition of health condition in public debates regarding the COVID-19 outbreak has paradoxically led to the invisibility of the essence of vulnerability, which is the greater likelihood of the presence of health problems. However, these health problems are not determined by age, nor are they limited to a group of people above a clearly defined age limit. Homogenization of age groups obscures this fact and presents all older individuals as automatically vulnerable and all younger people as not at risk. This perception of age groups in relation to the pandemic produces problematic effects. For example, according to this logic, chronological age becomes a relevant criterion for determining access to certain goods that were not previously perceived as being allocated based on age. The Italian Society for Anesthesia, Analgesia, Resuscitation and Intensive Care Medicine (SIAARTI) has issued recommendations in connection with the COVID-19 pandemic for healthcare professionals in intensive care units that explicitly mention the possibility of setting an age limit for access to health care and equipment. The authors of the recommendation mentioned that in a crisis situation when equipment necessary for patient survival is limited,

criteria for ICU admission (and discharge) may need to be driven not only by the principles of clinical appropriateness and proportionality of care, but also by criteria of distributive justice and appropriate allocation of the healthcare resources, that may be more limited than usual.

(Vergano et al. 2020: 1)

The patient's age and the estimated number of years the patient's life can be extended by administering treatment are some of the criteria to be considered when deciding who will have access to adequate care ${ }^{4}$ (ibid.). 
These recommendations have provoked a wave of critical debates regarding healthcare ethics, the discussion of which is beyond the scope of this chapter. Nevertheless, this example illustrates that the need to recognize diversity within age groups, which is one of the pillars of contemporary (social) gerontology, is easily forgotten within specific healthcare policies formulated during a crisis situation.

To understand the inability to integrate some key premises of the gerontological agenda of the past decades (such as the emphasis on diversity among older people) into efficient social policies, we also have to address the very roots of gerontology as a discipline. As pointed out by Fletcher (2021), it was inevitable that COVID-19 would be categorised by age in the research because our empirical tradition is based on the study of society through conventional categories. Gerontology as a discipline presupposes the existence of a specific population of older people that can and should be studied via a separate discipline. Fletcher suggests that chronologically based measures are simultaneously pragmatic, evidence-based and ageist. This paradoxical relationship is caused by an often unacknowledged 'epistemic ageism' that is manifested in conventional biosocial research on aging and that represents an understandable means of translating complex realities into a demarcated field of study. He points out that 'The evidence base manifests a type of deep-rooted ageism and is alienated from the circumstances of real persons, yet it simultaneously draws our attention to life-threatening risk and inspires a practicable means of lowering that risk' (Fletcher 2021: 489). We have frequently grounded our study of aging in the paradoxical assumption that there is something special about chronological age that should justify the study of older people as a specific population, simultaneously stressing the heterogeneity of this population, which should lead us toward rejecting the idea that there is something that homogenises the 'older' population as such. The debates regarding age-based measures in the time of the pandemic show how crucial and persistent the category of chronological age was and is in social and health policy.

The way in which the risks surrounding COVID-19 have been portrayed and addressed reflect structural problems related to the perception of the role of older people in society. These problems were not caused by this pandemic. In many cases, however, the coronavirus pandemic has acted as a magnifying glass, making these issues more visible. We believe that critical reflection is needed to analyse what kind of messages are brought to light through this glass concerning old age and the importance of the way chronological age is constructed. Thus, the aim of this chapter is to contribute to the discussion regarding the impact of the coronavirus pandemic on intergenerational solidarity and relationships. We argue that the way the pandemic has been framed in public debates and healthcare policies may influence our perception of age groups and possibly lead to intergenerational antagonisms.

The discussion of the (non)existence of intergenerational conflict has a long tradition in gerontological analysis. Such debates have focused mainly 
on public transfers, suggesting that expenditures related to pensions and health care for the growing number of older people in society may disrupt the social contract between generations (Binstock 2010: 3). This chapter focuses on the assignment of different levels of health risk as a source of potential intergenerational tensions. We argue that the current pandemic may stimulate intergeneration antagonism in a new way. As outlined previously, COVID-19 impacts different age groups differently. This fact may strengthen intergenerational solidarity. (This chapter also addresses how the distribution of different risk levels have facilitated solidarity between generations.) However, we argue that the way chronological age has been mobilized in the debates regarding the pandemic may in the long run contribute more to intergeneration antagonism. In this chapter we outline three processes that have accompanied public discourses on the COVID-19 pandemic and that may significantly shape social perceptions of chronological age and the position of older people in society. Firstly, as already explained, chronological age was established as a significant vector defining human positioning in society during the pandemic. Older age was essentialized as a type of health condition. Age groups, in the public discourse, were constructed as homogenous and united through the idea of (different levels of) risk. Secondly, contact between members of different generations was systematically established as one of the main risks for contracting COVID-19. This situation may further strengthen age segregation and distance between generations. However, the two processes may not necessarily contribute to intergenerational conflict. We argue that it is mainly the way the nature of risks and the character of the pandemic has been communicated that has led to the paradoxical position of systematically describing the lives of older people as more dispensable while simultaneously highlighting their protection as justification for society-wide measures that have a significant impact on all citizens. This chapter suggests that this paradox, together with the essentialisation of chronological age and age segregation, may give rise to new forms of intergenerational antagonism.

\section{Age segregation and the risk of intergeneration contact}

We can already find numerous studies addressing the manifestations of ageism aimed mainly at older people that have accompanied public debates regarding the pandemic and the measures that should be followed (Ayalon 2020; Beridge \& Hoovman 2020; Ehni \& Wahl 2020). We argue that these manifestations need to be interpreted primarily in the context of an agedivided society, which has become part of the communication of the 'fight' against the coronavirus infection. As Hagestad and Uhlenberg (2006) noted, we live in a society characterized by institutional, spatial and cultural age segregation. Without personal contact, the members of different age groups easily became 'the others'. Age segregation reproduces ageism and supports the isolation of older people. Institutional arrangements that 
separate age groups restrict opportunities to form cross-age relationships. In that respect, family represents a crucial context within our age-divided society where people of different generations can gather; indeed, it is becoming one of the last islands where strong relationships are formed across generations (ibid).

Communication on the nature of the risk associated with the pandemic through the language of separate age groups has established relatively impermeable age-group boundaries. Age-based restrictions targeting older people were introduced in some countries. These measures included recommendations regarding self-isolation for people of a certain age $(65+$ or $70+)$, and similarly, even formal restrictions, such as in the case of the United Arab Emirates, where young children under the age of 12 and people over the age of 60 were not allowed to enter malls, supermarkets, and some restaurants. Other states, such as, for example, the Czech Republic, introduced, in spring 2020, special shopping hours for people aged 65+ (in that time, no younger people were allowed in the shop, but older people were not restricted to attending shops outside those special hours). Israel regulated the number of workers who were allowed to work in shared spaces, while employees aged 67-plus were explicitly requested to stay home (CTECH, 2020).

Looking for a way to minimalise social contact, most of the countries that were impacted by the pandemic introduced some type of lockdown. This was, of course, a very expensive and often economically devastating solution. In contexts where a health risk is distributed unevenly among the various groups, the debate regarding intergenerational solidarity inevitably arises. Consequently, this debate was often framed by the idea of age-based lockdowns as a possible (and especially economically sustainable) solution. Suggestions that isolating older people would be a more economically effective and a generally less harmful policy approach compared to full lockdowns were repeatedly made in various contexts. Those debates were framed by the discussion regarding intergenerational solidarity, pointing out that the young had not been treated in a way that was fully ethically justifiable since they were at milder risk from the virus and therefore had less to gain from lockdowns. However, they would simultaneously bear a bigger burden of the economic cost of the policy measures (Rens \& Oswald 2021). The imaginability of this solution is grounded in the idea that it is somehow socially and ethically acceptable to segregate older people because they are not essential for the running of society. This argument not only downplays their role in the economy but also suggests that it is possible for society to function and for younger people to live their lives 'as usual' without the participation of older people. The lightness in which those arguments were integrated into (not only) debates regarding the public measures illustrates the persistent invisibility of older people in the social imagination of 'productivity' and in terms of their social contributions, despite all the effort that has been made to deconstruct such stereotypes. 
A study by Israeli researchers published in October 2020 even suggested that age separation was key to tackling the epidemic. The mathematical model presented in the chapter suggested that if people from just one household came together and excluded any other contacts from different age groups (which could be compensated for by other contacts, but only within their own age group), then the number of deaths associated with COVID-19 would fall by as much as $62 \%$. If people just from the same age group met, the model predicted a reduction in deaths in Israel by up to 93\% (Mizrahi et al. 2020). The authors were aware that restricting social contacts was problematic, especially in the case of older people, as they are more often at risk of loneliness. Therefore, the study did not propose social isolation as a solution, but isolation within age groups.

The COVID-19 pandemic thus brought not only the perception of social contact as a form of threat, but also the re-labeling of intergenerational encounters as a major risk factor (especially for older people, but also for society as a whole). It thus brought with it fundamental challenges for gerontology and related disciplines, within which there is a long-term consensus on the benefits and fundamentally positive role of intergenerational ties. The above-cited study by Mizrahi, Shekhidem, and Stern (2020) suggested that the disease spread not because people met, but because there was contact between people from different age groups. As the authors pointed out, the reason for such a significant decrease in mortality in the monitored models was the fact that the mild course of the disease was characterised by a relatively high number of people who had caught the infection without visible symptoms but were still infectious to those around them. These people did not tend to break off their social contacts. Older people were viewed as less likely to be asymptomatic and, according to the study, they transmitted the disease less often. Thus, the boundaries between age groups were not only established with regard to the different risks of a more severe course of the disease, but also via their different roles in disease transmission. The message about the dangers of intergenerational encounters therefore became an important part of pandemic risk communication. For example, the Israeli Minister of Defense emphasised that the most important thing was to separate young people from older people, and he described the situation where a grandmother would meet and hug her grandchildren as the most dangerous combination (Ayalon 2020). Part of the communication of measures aimed at reducing the spread of the disease was the message that intergenerational contact was a dangerous risk factor.

The emergence of COVID-19 pandemic significantly influenced the discussion regarding intergenerational solidarity and contact. It brought an important change in the way we think about what intergenerational solidarity means. Social contact, touch, and physical presence represent an important way of expressing our concern and care for our close ones. The pandemic led to a dramatic redefinition of what care and concern may mean, proposing social distancing as a way of expressing those feelings. The call to 
reduce contact between extended family members and take precautions in relation to older people who are at greater risk is, of course, not a problem in itself, but rather it is an incentive to think about how intergenerational solidarity can be fulfilled in other ways. As the German Chancellor emphasized in her speech, the emphasis on limiting contact between younger and older family members should be seen primarily as a challenge to look for other, additional forms of intergenerational support inside and outside the family. ${ }^{5}$ In this respect, during the initial stages of the pandemic, we also witnessed (especially, but not only) the vast intensity of intergenerational solidarity and the responsibility that many young people felt towards older people. Krastev (2020) observed that the experience of 'staying home' helped younger people to empathise with their parents and grandparents, who may have already spent more of their time at home and may have experienced health-related anxieties before the onset of the pandemic. This shared experienced may, therefore, potentially reinforce the understanding and solidarity between individuals from different age groups. At the same time, the restriction related to the pandemic made us experience what it means when contact between generations is lacking. Thus, it is possible to hope that, among other things, the importance and need for intergenerational ties have become evident through their short-term involuntary (physical) interruption. However, in the next section of this chapter, we suggest that the problematic position of chronological age and older people in the debates regarding the COVID-19 pandemic have the potential to alienate the experiences of different age groups and stimulate new forms of intergenerational antagonisms.

\section{Narratives of a 'stolen future' and intergenerational antagonism}

The relationship between age and the risk of experiencing a serious progression of COVID-19 has emphasised a key feature of the disease: it significantly affects the dynamics of the relationship between the generations. It has its positive effects that cannot be ignored (whether it is, for example, the activities of young people helping with food delivery or their volunteering in healthcare facilities). However, we suggest that with respect to intergenerational dialogue, age segregation and the discourses that accompany (and legitimise) the measures in response to pandemic will, instead, exacerbate antagonisms between the generations. In his essay, Ivan Krastev predicted that intergenerational conflict will escalate as the duration of the crisis caused by COVID-19 increases. According to Krastev, this conflict is strengthened, on one hand, by different economic effects of the crisis on different generations. At the same time, different levels of risk perception among younger and older people may lead to different patterns of behaviour in response to the pandemic. As a result, older people may feel threatened by young people's reluctance to adapt to rules that may reduce risks 
(Krastev 2020). Both moments that Krastev mentioned point to the possible rise of antagonisms between the generations caused by feeling that the other generation may be 'stealing your future'. The COVID-19 pandemic thus mobilises, among other things, the narrative, which is a key part of the debate on the nature of the intergenerational conflict. The idea that the older generation lives on the debt of the younger generation is an essential element of the debate on the risks of an aging population and the sustainability of the pension funding system (Binstock 2010). Similarly, at the beginning of March in the Czech Republic, economists debated the possibilities of quantifying the value of human life to enable the determination of the limit at which its rescue (at the expense of other societal economic losses) still makes sense. ${ }^{6}$ Although the authors of these considerations do not explicitly address the role of chronological age, its implicit presence cannot be avoided. The governor of Texas summed up this reasoning more explicitly in a television interview, mentioning that grandparents would like to sacrifice themselves for the sake of their grandchildren's economic futures. ${ }^{7}$ The debates over the approach to dealing with the pandemic, therefore, also include the narrative on 'sacrifice', which places fundamental demands on the older generation hand in hand with the idea of a 'disappearing' future for younger generations, 'stolen' by those who have already lived out most of their lives. Such narratives logically represent an explosive cocktail of intergenerational antagonism. Materialisation of this antagonism is reflected in the hashtags 'Boomer Remover' that appeared in March, referring to the idea of COVID-19 as a tool for effectively relieving society of the burden of older people and for solving problems with the pension and healthcare system or unemployment (Meisner 2020).

The coronavirus pandemic alone, of course, cannot be considered as the sole and primary source of this intergenerational antagonism. As Ayalon (2020) asserted, the pandemic entered a society already divided by conflicts, many of which are framed in terms of generational affiliation. The generation of baby boomers (i.e. people born between the mid-1940s and the mid-1960s) is often described as having lived in a time of economic prosperity and at the same time held responsible for a number of environmental challenges facing future generations, the sustainability of pensions or the opportunity for younger generations to reach the same standard of living the boomers enjoyed (Bristow 2015). Such rhetoric often accompanies youth movements that emphasise the need for changes in environmental policy. Members of student environmental movements often criticise the older generation for not being willing to change the lifestyle they have become accustomed to, at the cost of the consequences that those lifestyles will bear on their children and grandchildren. ${ }^{8}$ The idea of a 'stolen future' is certainly not a new narrative. However, the way in which the COVID-19 disease and the policies associated with it are described brings new aspects that change the dynamics of this narrative. 
The fact that the fatal progression of the disease mainly affects older people became a key tool mobilised to calm the public and to avoid the panic caused by the emergence of this new disease. Within the discourses on risk, this feature of COVID-19 symbolically differentiated this pandemic from other similar events in the past or expected other (potentially more serious) epidemics in the future. The reference to chronological age was an integral part of the report on victims of COVID-19 (especially) at the beginning of the pandemic, the purpose of which has undoubtedly been to highlight the fact that the vast majority of victims were advanced in age and that the chronology of life and death has not been fundamentally broken. While the reference to the serious progression of the disease affecting older people more often has undoubtedly served as key information to reassure the public, its unintended consequence is that it has reinforced the idea that the lives of certain people have a potentially different value than the lives of others (and this value may be related, among other things, to their age). As explained by Frazer et al. (2020), in the COVID-19 cases involving the deaths of younger people, the media has provided detailed personal stories, while the deaths of hundreds of thousands of older people have been reported only in the form of statistics.

Some types of vulnerabilities are influenced or reinforced by social factors. We should keep this in mind even when considering the vulnerability of older people. As noted by Berridge and Hooyman (2020: 2), although older people are generally more vulnerable to the more serious progression of the disease, the vulnerability of people living in long-term care institutions is further reinforced by the nature of these institutions, where more people live side by side in a small space and are cared for by a small number of carers. Almost half of all COVID-19 deaths involved clients in longterm care facilities. Available statistics indicate that $53 \%$ of deaths from COVID-19 in Italy, 57\% in Spain and 45\% in France involved clients of longterm care facilities (Comas-Herrera \& Zalakain 2020). In some countries, deaths from COVID-19 that occur in care homes are not recorded in the official statistics. Long-term care facilities for older people were deprioritised in terms of interventions at the beginning of the crisis and experienced a lack of personal protective equipment (Age Platform Europe 2020). The protection of the most vulnerable has become the headline of the need to fundamentally interfere with the running of society. However, the places where the most vulnerable are concentrated have paradoxically too often remained on the margins of interest. These moments reflect the structural disadvantages that older people face in society, regardless of the presence of the pandemic. Nevertheless, the way in which the pandemic has been portrayed and how the response to it has been formulated systematically constructed the idea that the value and meaning of human life can be derived from a chronological age. Older people in this context acted as a group that can be 'left' to die.' 
COVID-19 is presented primarily as a disease that severely affects older people. However, the measures that were supposed to protect the population have an impact on the daily lives of all citizens, probably more fundamentally at the economic level, especially on younger people. In his book, Ivan Krastev (2020) referred to reports that indicated that up to $52 \%$ of people under the age of 45 have either lost their jobs, been forced to go on leave or had their working hours reduced due to policies related to the pandemic. On one hand, older people may feel more endangered by the disease and, therefore, feel the impact of the pandemic more intensively. On the other hand, however, the economic impact of the measures has the potential to have a greater impact on younger and middle-aged people who are in or will be entering the labour market. These measures are taken in the name of a risk that is strongly framed by chronological age and to protect the population (which, given the way in which the risks are presented, mainly involves older people). The way in which the COVID-19 pandemic has affected public policies, thus, sets into motion several processes that reinforce intergenerational antagonism. It alienates the experience of this crisis situation between the various generations, who, moreover, are pitted against each other through the narrative of the 'stolen future' - whether within the narrative of young people who endanger older people with their irresponsibility or older ones whose protection costs young people too much. This sentiment is further reinforced by the paradox that all individuals are expected to subordinate their lifestyle and future economic prospects to protection against something that is described as a risk primarily to those who are systematically constructed as more easily dispensable.

\section{For further discussion...}

In the context of the events associated with the COVID-19 pandemic, we have witnessed the expansion of stereotypical depictions of age groups. As pointed out by of Morrow-Howell, Galucia and Swinford (2020: 4): 'We will have to regain any hard-won advances in reducing the external and internal ageism exacerbated in this pandemic'. This concerns both the problematic conceptions of chronological age and the stereotypical portrayal of older people, as well as the ideas that people are able to internalise regarding their own aging. Most of us have experienced feelings of helplessness in the face of this pandemic. However, no one should feel hopeless because he/she thinks that based solely on his/her age will he/she not receive adequate health care. Discussions about the need for 'sacrifice' in the case of the older generation or the criterion of chronological age when deciding who will receive what health care can easily evoke in older people a sense of distrust about whether their lives matter to others.

The different probability of severe COVID-19 in different groups has understandably and correctly led to the discussion regarding age-based policy measures that could protect the most vulnerable groups and simultaneously 
provide (economically) sustainable conditions in society. Two prominent aspects became part of this discussion. First, that it is the intergenerational contact that it the problem (or at least one of the major problems) and secondly, that to isolate and lock down older people was viewed as a solution (or at least as a short-term solution, possibly until there was a vaccine and/ or other medical treatments). The pandemic situation has led not only to the essentialisation of the category of 'old people' but also to the consolidation of the idea age groups as separate. Contact between members of different (homogenous) generations was constructed as one of the fundamental problems in the spread of the disease. This discussion impacts not only the policies introduced during the time of pandemic but should also be critically analysed to inform our future policies and research outside the debates regarding pandemic-related measures. Those discussions regarding age-based segregation not only challenge some key premises stressed by current gerontological research (e.g., the benefits and crucial role of intergenerational contact) but also reveal some structural problems regarding the way in which chronological age is mobilised in social policies and perceptions of the role of older people in society. We should therefore also use this discussion as a starting point for a critical debate and as a magnifying glass that can enable us to identify fundamental challenges that gerontology and its related disciplines may encounter. The COVID-19 pandemic very seriously disrupted our daily lives and required a number of measures, the nature of which often corresponded to the need to resolve the crisis quickly, sometimes even at the cost of challenging some key principles that have guided our approach to chronological age and older people in our previous policies. As Sarah Harper notes (Harper 2020: 424): 'Pragmatic policy making is one thing in a crisis, long term institutionalised ageism is another'.

The way in which chronological age and the role of older people have been presented in public debates about COVID-19 not only strengthens the age division of society but also intervenes in intergenerational relations and solidarity. Although we have witnessed (especially at the beginning of the spread of the disease) a rise in solidarity aimed at helping older people, the way in which age is mobilised in public discourses and policies reinforces antagonism between members of different generations. This antagonism stems from both the way age is treated in discussions about COVID-19 and the paradoxical position of older people in portraying this pandemic. In the public discussions surrounding the COVID-19 pandemic, the lives of older people are systematically described (and perceived) as more dispensable and implicitly less valuable. At the same time, however, the protection of the older adults as a group is becoming a justification for society-wide measures that have a significant impact on all (and often, very painfully on those who do not feel threatened by the disease due to their age). We believe that this paradox gives rise to forms of intergenerational antagonism that further deepen the age division of society. 


\section{Notes}

1 The work on this study was supported by Czech Science Foundation (grant no. 21-16738S) and by the Charles University Research Programme "Progres" Q18 Social Sciences: From Multidisciplinarity to Interdisciplinarity.

2 Mortality rates are higher for people over 60 and for people with pre-existing health problems [8]. For example, the rate of death in the age group 65-74 is 95 times higher compared with 18- to 29 -years-old (which is the age group that accounted for the largest cumulative number of COVID-19 cases compared to other age groups). The death rate in 75- to 84-years-old is 230 times higher compared with this reference group [7].

3 Baulisová, K.: “Nemoc starých, která děti milosrdně vynechává.” MFDnes 11.3.2020.

4 In Germany, the Ethics Committee (Deutscher Ethikrat) issued an ad hoc statement for situations involving the lack of resources needed to provide adequate health care. These recommendations explicitly reject the age criterion and emphasise the prospect of the successful treatment of the patient, which depends on the individual's medical condition [10].

5 Appeal to the people living in Germany: Angela Merkel's speech about the Corona virus in full. (https://ga.de/ga-english/news/angela-merkel-s-speech-aboutthe-corona-virus-in-full_aid-49639811).

6 Tůma, Z. M, Hampl: "Bývalí šéfové ČNB Tůma a Hampl: necháme v zájmu ochrany života umř́t celou českou ekonomiku?” Hospodářské noviny 19.3.2020.

7 Rodriguez, A.: "Texas' lieutenant governor suggests grandparents are willing to die for US economy." USA Today 24.3.2020. Available at: https:// eu.usatoday.com/story/news/nation/2020/03/24/covid-19-texas-official-suggestselderly-willing-die-economy/2905990001/

8 In this context, it is no coincidence that one of the hoaxes spread in connection with the COVID-19 pandemic in the Czech Republic worked with a fake print screen of the Friday for Future student climate movement Facebook page, where young people praised the benefits of the pandemic for the future well-being of the Earth, as it will enable the next generation to repair the damage done to the environment by the previous ones. The fake contribution sought to exaggerate the degree of intergenerational antagonism that is often present in the narrative of the stolen future' that the student movement mobilises in relation to the inability of political representation (recruited from the older generation) to face climate challenges.

9 The cases of abandoned residents and elderly patients in retirement homes reported from Spain illustrates this approach in a shocking way (https://www.bbc. com/news/world-europe-52014023).

\section{References}

Age Platform Europe. COVID-19 andhuman rights concerns for older persons (updated version 18May2020). [cit 13.8.2020]. Availableat:https://www.age-platform.eu/sites/ default/files/Human $\% 20$ rights $\% 20$ concerns $\% 20$ on $\% 20$ implications $\% 20$ of $\% 20$ COVID $\% 2019 \% 20$ to $\% 20$ older\%20persons_Final_18May2020.pdf

Ayalon L. There is nothing new under the sun: Ageism and intergenerational tension in the age of the COVID-19 outbreak. International Psychogeriatrics, 1-4. 2020. https://doi.org/10.1017/S1041610220000575

Berridge C., Hooyman N. The consequences of ageist language are upon us. Journal of Gerontological Social Work 63 (6-7): 508-512. 2020. https://doi.org/10.1080/01 634372.2020 .1764688 
Binstock R. H. From compassionate ageism to intergenerational conflict? The Gerontologist 50 (5): 574-585. 2010. https://doi.org/10.1093/geront/gnq056

Centers for Disease Control and Prevention. Risk for Covid-19 infection, hospitalization and death by age group. [Updated 2021 Jun 24] [online]. [cit 9.7.2021]. Availableat:https://www.cdc.gov/coronavirus/2019-ncov/covid-data/investigationsdiscovery/hospitalization-death-by-age.html

Comas-Herrera A., Zalakain J. X. Mortality associated with COVID-19 outbreaks in care homes: Early international evidence. [online]. International Long-Term Care Policy Network, CPEC-LSE. 2020. [cit 10.7.2020]. Available at: https://alzheimeriberoamerica.org/wp-content/uploads/2020/04/Mortality-associated-withCOVID-12-April-3.pdf

CTECH. (2020). Israel rolls back Covid-19 restrictions as number of sick stabilizes. https://www.calcalistech.com/ctech/articles/0,7340,L-3809065,00.html, accessed 27 September, 2021.

Ehni H. J., Wahl H. W. Six Propositions against Ageism in the COVID-19 Pandemic. Journal of Aging \& Social Policy 32 (4-5): 515-525. 2020. https://doi.org/10.1080/ 08959420.2020 .1770032

Fletcher, J. Chronological quarantine and ageism: COVID-19 and gerontology's relationship with age categorisation. Ageing and Society 41 (3): 479-492. 2021. https:// doi.org/10.1017/S0144686X20001324

Fraser S., Lagacé M., Bongué, B., Ndeye N., Guyot J., Bechard L., Garcia L., Taler V., Adam S., Beaulieu M., Bergeron, C. D. Ageism and COVID-19: What does our society's response say about us? Age and Ageing 49 (5): 692-695. 2020. https://doi. org/10.1093/ageing/afaa097

Gilleard C., Higgs P. COVID-19 amplifies but doesn't alter the chronology of life and death. [online]. TransformingSociety. 2020. [cit 1.7.2020]. Available at: http:// www.transformingsociety.co.uk/2020/05/20/covid-19-amplifies-but-doesntalter-the-chronology-of-life-and-death/

Hagestad G. O., Uhlenberg P. Should we be concerned about age segregation? Some theoretical and empirical explorations. Research on Aging 28 (6): 638-653. 2006. https://doi.org/10.1177/0164027506291872

Harper, S. The COVID-19 Pandemic and older adults: Institutionalised ageism or pragmatic policy? Population Ageing 13: 419-425. 2020. https://doi.org/10.1007/ s12062-020-09320-4

Israeli rolls back as Covid-19 restrictions as number of sick stabilize. [online]. Calcalist April 20, 2020. [cit 9.7.2021]. Available at: https://www.calcalistech.com/ ctech/articles/0,7340,L-3809065,00.html

Krastev I. Už je zítra?: Aneb jak pandemie mění Evropu. Praha: Nakladatelství Karolinum. 2020.

Meisner B. A. Are you OK, Boomer? Intensification of ageism and intergenerational tensions on social media amid COVID-19. Leisure Sciences, 1-6. 2020. https://doi. org/10.1080/01490400.2020.1773983

Mizrahi L. H., Shekhidem A., Stern, A. Age separation dramatically reduces COVID-19 mortality rate in a computational model of a large population. Open Biology 10 (11). 2020. https://doi.org/10.1098/rsob.200213

Morrow-Howell N., Galucia N., Swinford E. Recovering from the COVID-19 pandemic: A focus on older adults. Journal of Aging \& Social Policy 32 (4-5): 526-535. 2020. https://doi.org/10.1080/08959420.2020.1759758 


\section{Jaroslava Hasmanová Marhánková}

Rens van T., Oswald A. J. Age-based policy in the context of the Covid-19 pandemic: How common are multigenerational households? [online]. Warwick Economics Research Papers No: 1315. 2020. [cit 9.7.2021]. Available at: https://warwick.ac.uk/ fac/soc/economics/research/workingpapers/2020/twerp_1315_-_oswald.pdf

Vergano M., Bertolini G., Giannini A., Gristina G. R., Livigni S., Mistraletti G., Riccioni L., Petrini F. Clinical ethics recommendations for the allocation of intensive care treatments in exceptional, resource-limited circumstances: The Italian perspective during the COVID-19 epidemic. Critical Care 24 (165). 2020. https://doi. org/10.1186/s13054-020-02891-w 